\title{
Landing Risk Assessment of Carrier-Based Aircraft Based on Fuzzy Multi-Attribute Group Decision Making
}

\author{
Hai-tao Jiang, Hui Li and Xiao-dong Su \\ School of Computer and Information Engineering \\ Harbin University of Commerce \\ hrbcu_lh@163.com
}

\begin{abstract}
In allusion to the special characteristic of longitudinal loop risk assessment in landing process of carrier-based aircraft, this paper extends the concept of decision-maker, and proposes a method of fuzzy multi-attribute decision making with normal fuzzy linguistic variables as decision-making information. Based on the establishment of carrier-based aircraft landing model, the expressions of risk evaluation indicators are ensured, and the relative attribute weight is calculated by the simulation of the safe flight area in landing process. The application of risk assessment is implemented by analogy between standard points and decision-maker. The analysis of numerical examples shows that the method is practical and the application in risk evaluation is reasonable. Multipoint decision information is complete and decision results accord with distributions of touchdown points. Comprehensive evaluation of flight safety with different pilots can be realized.
\end{abstract}

Keywords: Normal Fuzzy Number; Multi-Attribute Group Decision Making; Safe Flight Area; Relative Attribute Weight; Landing Risk Assessment

\section{Introduction}

It is well-known that landing approach after training and battling is so hardship for carrier-based aircraft because of numerous uncertain factors. To cultivate the qualified pilots and evaluate the manipulate capabilities of different pilots precisely, it is important to make a decision making for some approaches [1].

Multi-attribute group decision making utilizes attribute information and attribute weights in advance to order and pick out the best one for a group limited alternatives [2]. As the complexity and fuzziness of objects in real, we always express decision information as linguistic variables or intervals [3]. Multi-attribute group decision making based on linguistic variables has been the research focus in decision making domain [4-8].

To solve the landing risk evaluation problem of carrier-based aircraft, we first present a brief problem description for risk assessment. The normal fuzzy linguistic variables is expressed for decision making, and a developed approach to solve multi-attribute decision making for landing risk is extended. An illustrative example is shown for proving the rationality of new decision method.

\section{Problem Description}

\subsection{Traditional LSO Decision Making}

The time from glideslope with Fresnel Lens Optical Landing System (FLOLS) information to touchdown point on carrier is so long, and it is waste to evaluate the whole course. The real evaluation aims at four standard points during landing process: $X($ start), IM(in the middle), IC(in the close), AR(at ramp), as shown in Figure 1. 


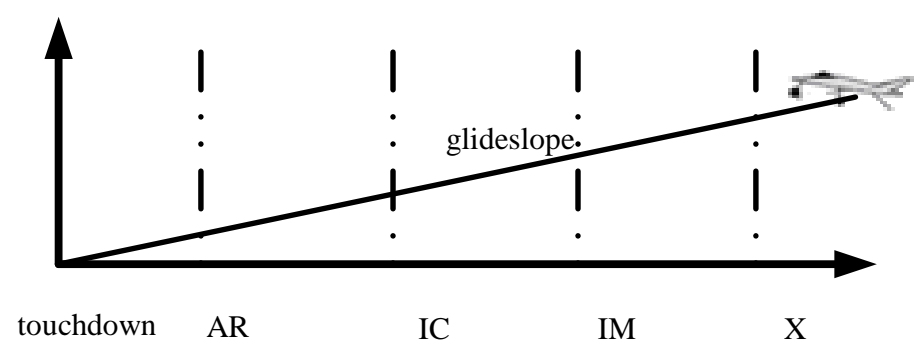

Figure 1. Reference Points on the Final Approach

During landing process, the flight status of carrier-based aircraft should be guided by Landing Signal Officer (LSO) [10]. LSO, pilot and aircraft constitute a whole landing control system, as shown in Figure 2. After catching cable, LSO describes flight result from positions and gestures to evaluate operation capability, as shown in Table $1[9,11]$.

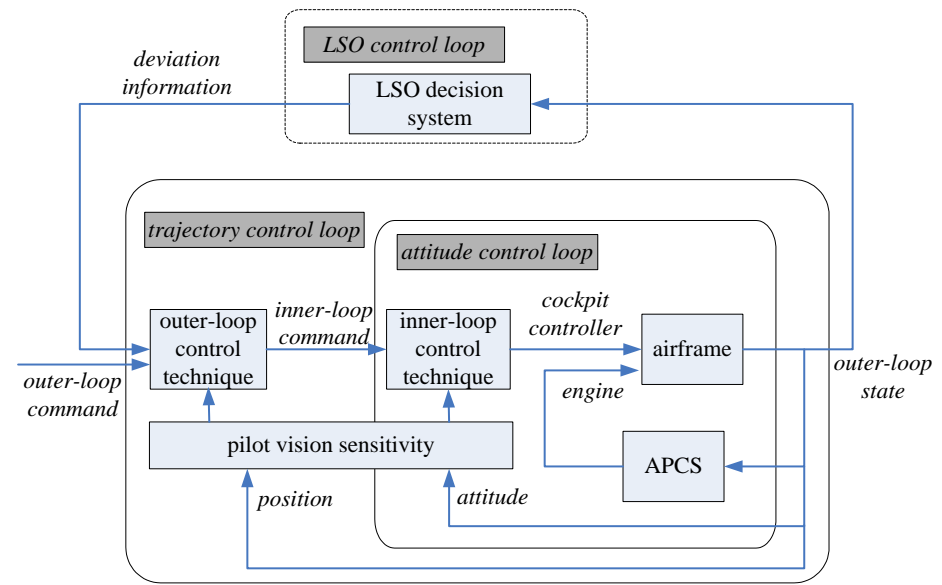

Figure 2. LSO-pilot-aircraft Landing System

Table 1. Assessment Chart of LSO

\begin{tabular}{|c|c|c|c|c|c|c|c|c|c|c|c|c|}
\hline \multirow{2}{*}{ Pilot } & \multicolumn{4}{|c|}{ GlideSlope } & \multicolumn{4}{|c|}{ Speed } & \multicolumn{4}{|c|}{ Rate of descent } \\
\hline & $\mathrm{X}$ & IM & IC & AR & $\mathrm{X}$ & IM & IC & $\mathrm{AR}$ & $\mathrm{X}$ & IM & IC & $\mathrm{AR}$ \\
\hline 1 & $\underline{\mathrm{H}}$ & $(\mathrm{H})$ & $\begin{array}{l}\mathrm{O} \\
\mathrm{K}\end{array}$ & $\begin{array}{c}\text { (LO } \\
\text { ) }\end{array}$ & $\begin{array}{c}\text { SL } \\
\mathrm{O}\end{array}$ & $\begin{array}{c}\text { (SLO } \\
\text { ) }\end{array}$ & $\mathrm{F}$ & $\underline{F}$ & NERD & (NERD) & $\mathrm{OK}$ & OK \\
\hline 2 & $\mathrm{LO}$ & $\begin{array}{c}\text { (LO } \\
\text { ) }\end{array}$ & $(\mathrm{H})$ & OK & OK & (F) & $\mathrm{OK}$ & $\begin{array}{c}\text { (SLO } \\
\text { ) }\end{array}$ & $\begin{array}{c}\text { (TMRD } \\
\text { ) }\end{array}$ & $\begin{array}{c}\text { (TMRD } \\
\text { ) }\end{array}$ & $\begin{array}{c}\text { (TMRD } \\
\text { ) }\end{array}$ & OK \\
\hline $\begin{array}{l}\cdots \\
\cdots\end{array}$ & & $\ldots$ & & & & & & & & & & \\
\hline $\mathrm{n}$ & $\begin{array}{l}\mathrm{O} \\
\mathrm{K} \\
\end{array}$ & $\mathrm{H}$ & $(\mathrm{H})$ & $(\mathrm{H})$ & $\underline{F}$ & (F) & $\begin{array}{c}\text { (SLO } \\
\text { ) }\end{array}$ & OK & (NERD) & OK & TMRD & $\begin{array}{c}\text { (TMRD } \\
\text { ) }\end{array}$ \\
\hline
\end{tabular}

In Table 1, GlideSlope $=\{\mathrm{H}=$ Very high, $\mathrm{H}=$ high, $(\mathrm{H})=\mathrm{a}$ little high, $\mathrm{OK}=\mathrm{OK}$, $(\mathrm{LO})=$ a little low, $\mathrm{LO}=$ low, $\mathrm{LO}=$ very low $\}$; Speed $=\{\mathrm{SLO}=$ very slow, $\mathrm{SLO}=$ slow, $(\mathrm{SLO})=\mathrm{a}$ little slow, $\mathrm{OK}=\mathrm{OK}, \quad(\mathrm{F})=\mathrm{a}$ little fast, $\mathrm{F}=$ fast, $\mathrm{F}=\mathrm{very}$ fast $\}$; $\mathrm{ROD}=\{\mathrm{NERD}=$ very smart, $\mathrm{NERD}=$ smart, $\quad(\mathrm{NERD})=\mathrm{a}$ little smart, $\mathrm{OK}=\mathrm{OK}$, $(\mathrm{TMRD})=$ a little large, TMRD=large, TMRD=very large $\}[9]$.

From Table 1, we know it is difficult to compare different pilots operation capabilities during the whole approach, and bring a convenience to comprehensive evaluation. 


\subsection{Fuzzy Multi-attribute Group Information Risk Decision Making}

Through analysis above, the key point for landing evaluation is how to utilize flight status at standard positions to evaluate the whole approach. Let glideslope standard positions be a discrete set of decision makers, and flight status description at different standard positions is a finite set of index, then landing risk evaluation will be a multi-attribute group decision making problem, as shown in Table 2.

Table 2. Decision Information of Decision-maker dk (Reference Point xk)

\begin{tabular}{cccc}
\hline & GlideSlope & Speed & ROD \\
\hline Pilot 1 & $s_{11}$ & $s_{12}$ & $s_{13}$ \\
Pilot 2 & $s_{21}$ & $s_{22}$ & $s_{23}$ \\
$\ldots \ldots$ & $\ldots \ldots$ & $\ldots \ldots$ & $\ldots \ldots$ \\
Pilot $\mathrm{n}$ & $s_{\mathrm{n} 1}$ & $s_{\mathrm{n} 2}$ & $s_{\mathrm{n} 3}$ \\
\hline
\end{tabular}

Suppose that LSO risk descriptions influenced by experience, knowledge and capabilities, the evaluation information $s_{i j}$ should be fuzzy linguistic variables [12]. As selecting course, Normal fuzzy linguistic variables are the most suitable one.

\section{Normal Fuzzy Linguistic Variables}

Definition 1: Let $\hat{s}_{\theta}=\left[x_{\theta}, \sigma_{\theta}\right]$ is normal fuzzy linguistic variable, as shown in Figure 3 , where membership function $\mu_{\hat{s}_{o}}(x): R \rightarrow[0,1]$ is $[13-15]$

$$
\mu_{\hat{S}_{\theta}}(x)=e^{-\left(\frac{x-x_{\theta}}{\sigma_{\theta}}\right)} \quad\left(\sigma_{\theta}>0\right)
$$

Where $\hat{s}_{\theta} \in \hat{S}, x_{\theta}$ and $\sigma_{\theta}$ are the expect and variance of normal fuzzy linguistic variable respectively [16].

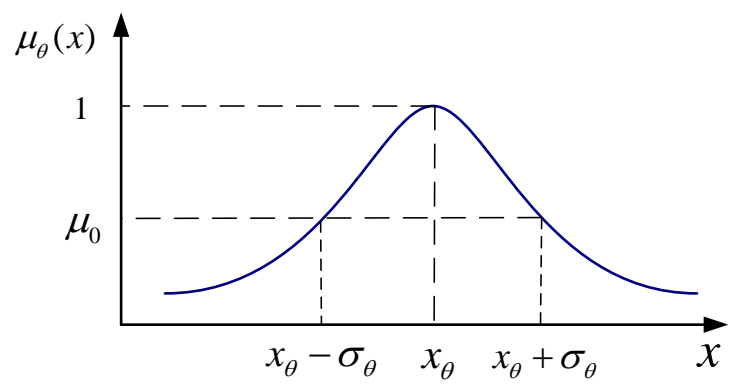

Figure 3. Normal Fuzzy Linguistic Variables

Let $\hat{s}_{1}=\left[x_{\theta_{1}}, \sigma_{\theta_{1}}\right]$ and $\hat{s}_{2}=\left[x_{\theta_{2}}, \sigma_{\theta_{2}}\right]$ are two normal fuzzy linguistic variable, and $\lambda \in[0,1]$, then:

$$
\begin{aligned}
& \text { (1) } \lambda \hat{s}_{1}=\lambda\left[x_{\theta_{1}}, \sigma_{\theta_{1}}\right]=\left[\lambda x_{\theta_{1}}, \lambda \sigma_{\theta_{1}}\right] ; \\
& \text { (2) } \hat{s}_{1}+\hat{s}_{2}=\left[x_{\theta_{1}}, \sigma_{\theta_{1}}\right]+\left[x_{\theta_{2}}, \sigma_{\theta_{2}}\right]=\left[x_{\theta_{1}}+x_{\theta_{2}}, \sigma_{\theta_{1}}+\sigma_{\theta_{2}}\right] .
\end{aligned}
$$

Definition 2: Let $\hat{s}_{1}=\left[x_{\theta_{1}}, \sigma_{\theta_{1}}\right]$ and $\hat{s}_{2}=\left[x_{\theta_{2}}, \sigma_{\theta_{2}}\right]$ are two normal fuzzy linguistic variable, the possibility degree $p\left(\hat{s}_{1} \geq \hat{s}_{2}\right)$ of normal fuzzy linguistic variable $\hat{s}_{1} \geq \hat{s}_{2}$ by $3 \sigma$ law is 


$$
p\left(\hat{s}_{1} \geq \hat{s}_{2}\right)=\max \left\{1-\max \left(\frac{\hat{s}_{2}^{+}-\hat{s}_{1}^{-}}{l_{2}+l_{1}}, 0\right), 0\right\}
$$

Where $\left\{\begin{array}{c}\hat{s}_{i}^{+}=x_{\theta_{i}}+2.58 \sigma_{\theta_{i}} \\ \hat{s}_{i}^{-}=x_{\theta_{i}}-2.58 \sigma_{\theta_{i}} \quad(i=1,2) . \\ l_{i}=\hat{s}_{i}^{+}-\hat{s}_{i}^{-}\end{array}\right.$

The possibility degree algorithm are:

(1) $0 \leq p\left(\hat{s}_{1} \geq \hat{s}_{2}\right) \leq 1,0 \leq p\left(\hat{s}_{2} \geq \hat{s}_{1}\right) \leq 1$;

(2) $p\left(\hat{s}_{1} \geq \hat{s}_{2}\right)+p\left(\hat{s}_{2} \geq \hat{s}_{1}\right)=1$, especially, when $\hat{s}_{1}=\hat{s}_{2}, p\left(\hat{s}_{1} \geq \hat{s}_{2}\right)=p\left(\hat{s}_{2} \geq \hat{s}_{1}\right)=1 / 2$;

(3)Let $p\left(\hat{s}_{1} \geq \hat{s}_{2}\right) \geq 1 / 2$ and $p\left(\hat{s}_{2} \geq \hat{s}_{3}\right) \geq 1 / 2$, then $p\left(\hat{s}_{1} \geq \hat{s}_{3}\right) \geq 1 / 2$;

(4)Let $p\left(\hat{s}_{1} \geq \hat{s}_{2}\right) \geq 1 / 2 \quad$ and $\quad p\left(\hat{s}_{2} \geq \hat{s}_{3}\right) \geq 1 / 2 \quad, \quad$ then $p\left(\hat{s}_{1} \geq \hat{s}_{2}\right)+p\left(\hat{s}_{2} \geq \hat{s}_{3}\right) \geq p\left(\hat{s}_{1} \geq \hat{s}_{3}\right)$.

Definition 3: Let $f: \hat{s}^{n} \rightarrow \hat{s}$, if $f\left(\hat{s}_{1}, \hat{s}_{2}, \ldots \hat{s}_{n}\right)=\omega_{1} \hat{s}_{1} \oplus \omega_{2} \hat{s}_{2} \oplus \ldots \oplus \omega_{n} \hat{s}_{n} \quad$, where $\omega=\left(\omega_{1}, \omega_{2}, \ldots \omega_{n}\right)^{\mathrm{T}}$ is weighted vector with $f, \omega_{j} \in[0,1], \sum_{j=1}^{n} \omega_{j}=1$, then we call is $\mathrm{n}$ dimensional normal fuzzy linguistic weighted average (NFLWA) operator.

$$
\text { N FLW A } \omega\left(\hat{s}_{1}, \hat{s}_{2}, \ldots \hat{s}_{n}\right)=\omega_{1} \hat{s}_{1} \oplus \omega_{2} \hat{s}_{2} \oplus \ldots \oplus \omega_{n} \hat{s}_{n}=\left[\sum_{j=1}^{n} \omega_{j} x_{\theta_{j}}, \sum_{j=1}^{n} \omega_{j} \sigma_{\theta_{j}}\right]
$$

\section{Landing Risk Evaluation of Carrier-Based Aircraft Based on Fuzzy Multi-Attribute Group Decision Making}

\subsection{Decision Making Parameters}

Let $\boldsymbol{X}=\left\{x_{1}, x_{2}, \ldots x_{m}\right\}$ be a discrete set of $m$ pilots as feasible alternatives, $\boldsymbol{U}=\left\{u_{1}, u_{2}, \ldots u_{n}\right\}$ is a finite set of flight status as attributes, and $\boldsymbol{D}=\left\{d_{1}, d_{2}, d_{3}, d_{4}\right\}$ is set of standard positions as decision makers. Suppose that $\omega=\left\{\omega_{1}, \omega_{2}, \ldots \omega_{n}\right\}^{\mathrm{T}}$ is the weight vector of attribute $u_{j}(j=1,2, \ldots, n)$, where $\omega_{j} \geq 0, \sum_{j=1}^{n} \omega_{j}=1$. Construct $\boldsymbol{R}_{\boldsymbol{k}}=\left(r_{i j}^{(k)}\right)_{m \times n}$ a decision matrix as shown below.

After confirming evaluation matrix $\boldsymbol{R}_{\boldsymbol{k}}$, the key point of risk evaluation is ascertaining attribute weighted vector $\omega^{(k)}$ which is given by decision maker to alternative $x_{i}$ and $\omega$ for synthesize attribute evaluation $r_{i}$.

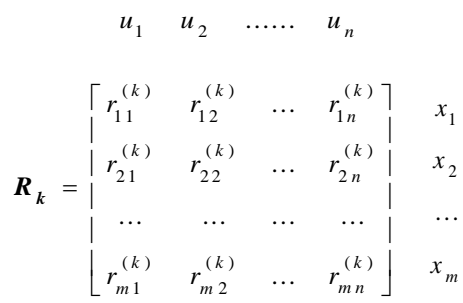




$$
\begin{cases}\omega_{i}^{(k)}=\frac{1-\lambda}{n}+\frac{\lambda}{n-1} & i \neq n \\ \omega_{i}^{(k)}=\frac{1-\lambda}{n} & i=n\end{cases}
$$

Where $\lambda=0.2, n=3$.

$\omega^{(k)}=\left\{\omega_{1}^{(k)}, \omega_{2}^{(k)}, \ldots \omega_{n}^{(k)}\right\}^{\mathrm{T}}$ is the relative attribute weight of aircraft flight status. [10] shows vertical loop flight status included glideslope position, attitude(velocity) and rate of sink. Where glideslope position and attitude(velocity) are major flight status, and rate of sink is the minor one.

$\omega=\left\{\omega_{1}, \omega_{2}, \ldots \omega_{t}\right\}^{\mathrm{T}}$ is the relative attribute weight of different standard positions, and there is no effective definition method. It confirms the Safe Flight Area (SFA) at standard positions through simulation analysis method, and gets $\omega_{i}$.

To arrive at the desired point of the deck accurately, the pilot must follow a path prescribed by the FLOLS glideslope. Further, the relationship of aircraft vertical position and SFA envelope could be judged by the distribution of touchdown points on the carrier deck.

Hook-to-ramp clearance is the distance between hook and carrier when aircraft is locating over the ramp, and it still influences the safety of aircraft approach. To ensure keeping enough hook-to-ramp clearance is necessary for keeping aircraft and carrier from colliding.

Considering the distribution of touchdown points and hook-to-ramp clearance, Safe Flight Region envelope at different standard points (Figure 1) will be established. In order to expound the method, IC point should be an example.

For the simulation, we consider aircraft position from the carrier is equal to 463 meters (IC point), desired velocity and angle of attack are respectively equal to 69.96 meters per second and 8.1 degrees. Preliminary glideslope deviations vary in the range of \pm 16 meters, 32 groups of the flight trajectories and touchdown points distribution are represented on Figure 4 and Figure 5.

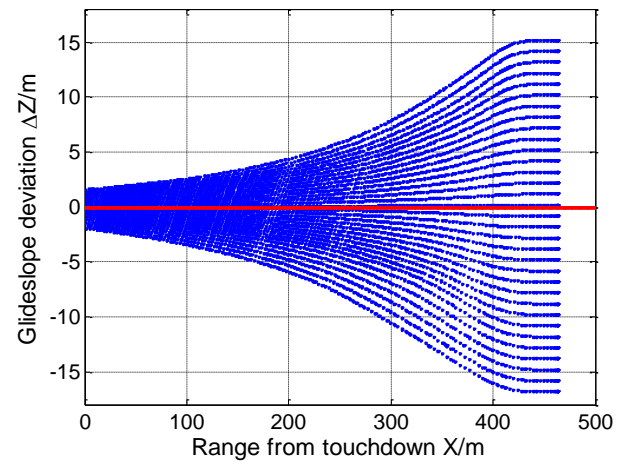

Figure 4. Glideslope Deviations Figure. 5 Distributions of Touchdown Curves

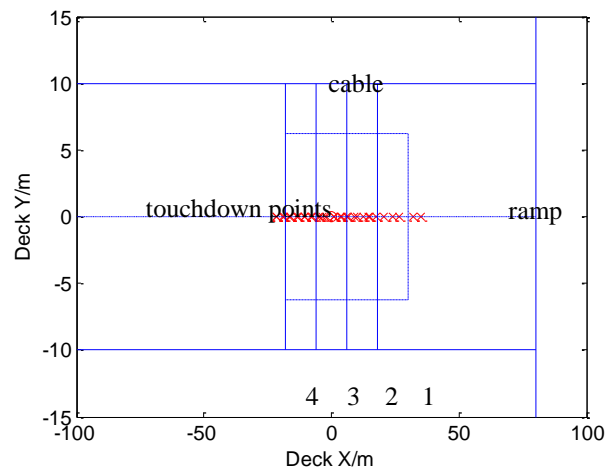

Points

As presented in Figure 5, According to the distribution of four cables, we directly obtain the longitudinal safe rectangle region on deck of carrier: $W_{\text {Deck }} \in[-18,30] \mathrm{m}$.

There is a risk when touchdown point is out of the Safe Rectangle Region, preliminary deviations should be counted by the range of touchdowns as presented in Figure 6. The longitudinal safe flight region at IC point is equal to: $z_{p_{r c}} \in[-15.2,11.9] \mathrm{m}$. 


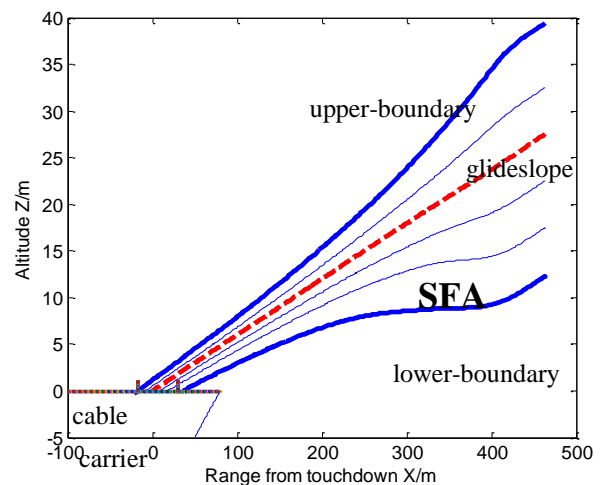

Figure 6. Touchdown Points and SFA

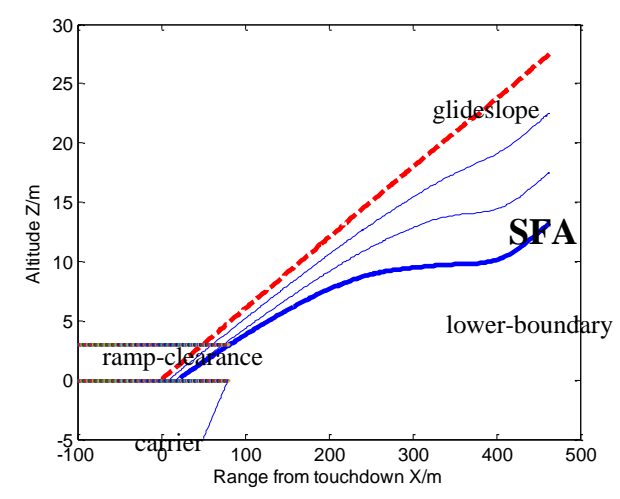

Figure 7. Ramp-clearance and SFA

The relationship of preliminary deviations and hook-to-ramp clearance is presented in Figure 7. To ensure the least clearance of 3 meters, the preliminary deviation at IC position is equal to: $z_{p, c}>-15.1 \mathrm{~m}$.

Considering the distribution of touchdown and hook-to-ramp clearance, the longitudinal Safe Flight Region at IC point is equal to: $z_{p_{1 c}} \in[-15.1,11.9] \mathrm{m}$.

Similar schemes are applied to the other standard points (X, IM, AR) as presented in Table II. The longitudinal safe flight region will be shown by curve fitting methods as presented in Table 3.

From Table 3, we know that the closer to carrier, the smaller for SFA, and the more risk for pilots. So the relative attribute weight relationship of standard positions is $\omega_{\mathrm{AR}}>\omega_{\mathrm{IC}}>\omega_{\mathrm{IM}}>\omega_{\mathrm{X}}$.

Utilize SFA to quantitate relative attribute weight:

$$
\omega_{i}=\frac{1}{z_{p_{i}}^{u p}-z_{p_{i}}^{\text {down }}} \quad(i=\mathrm{X} 、 \mathrm{IM} 、 \mathrm{IC} \text { or } \mathrm{AR})
$$

Normalized $\omega_{\mathrm{X}}=0.0403, \omega_{\mathrm{IM}}=0.0638, \omega_{\mathrm{IC}}=0.1231, \omega_{\mathrm{AR}}=0.7728$.

Table 3. Safe Flight Area on Reference Points

\begin{tabular}{ccccc}
\hline $\begin{array}{c}\text { Reference } \\
\text { point }\end{array}$ & $\begin{array}{c}\text { Lower- } \\
\text { boundary/m }\end{array}$ & $\begin{array}{c}\text { Upper-boundary } \\
/ \mathrm{m}\end{array}$ & $\begin{array}{c}\text { Ramp } \\
\text { clearance/m }\end{array}$ & $\begin{array}{c}\text { Safe flight } \\
\text { area/m }\end{array}$ \\
\hline $\mathrm{X}(3 / 4 \mathrm{~nm})$ & -43.5 & 39.6 & $>-42.8$ & {$[-42.8,39.6]$} \\
$\mathrm{IM}(1 / 2 \mathrm{~nm})$ & -29.2 & 24.4 & $>-27.7$ & {$[-27.7,24.4]$} \\
$\mathrm{IC}(1 / 4 \mathrm{~nm})$ & -15.2 & 11.9 & $>-15.1$ & {$[-15.1,11.9]$} \\
$\mathrm{AR}(80 \mathrm{~m})$ & -1.7 & 2.6 & $>-1.9$ & {$[-1.7,2.6]$} \\
\hline
\end{tabular}

\subsection{Decision Making Description}

The step of landing risk evaluation based on fuzzy multi-attribute group decision making are:

(1) For one multi-attribute group decision making problem, let $X=\left\{x_{1}, x_{2}, \ldots x_{m}\right\}$ be a discrete set of $m$ feasible alternatives, $U=\left\{u_{1}, u_{2}, \ldots u_{n}\right\}$ is a finite set of attributes, and $\boldsymbol{D}=\left\{d_{1}, d_{2}, \ldots d_{k}\right\}$ is a set of decision makers. Construct $\boldsymbol{R}_{\boldsymbol{k}}=\left(r_{i j}^{(k)}\right)_{m \times n}$ a decision matrix.

(2) Utilize the NFLWA operator to aggregate the attribute value $r_{i j}^{(1)}$ in the $i$ th column of the decision matrix $R_{1}$ into a overall attribute value of the alternative $x_{i}$ $(i=1,2, \ldots, m)$ : 


$$
r_{i}^{(k)}=\mathrm{NFLWA}_{\omega^{(k)}}\left(r_{i 1}^{(k)}, \ldots, r_{i n}^{(k)}\right)=\omega_{1}^{(k)} r_{i 1}^{(k)}+\ldots+\omega_{n}^{(k)} r_{i n}^{(k)} \quad(i \in M, k=1,2,3,4)
$$

(3) Use the NFLWA operator to aggregate the attribute value $r_{i}^{(k)}(i \in M, k=1,2,3,4)$ of the four standard positions into a overall attribute value of the alternative $x_{i}$ $(i=1,2, \ldots, m)$ :

$$
r_{i}=\operatorname{NFLWA}_{\omega}\left(r_{i}^{(1)}, \ldots, r_{i}^{(4)}\right)=\omega_{1} r_{i}^{(1)}+\ldots+\omega_{4} r_{i}^{(4)} \quad(i \in M)
$$

(4) Compare each $r_{i}(i \in M)$ by using the possibility-degree formula(2), then construct the possibility-degree matrix $\boldsymbol{P}^{(1)}=\left(p_{i j}^{(1)}\right)_{m \times m}$.

(5) The ordering vector $\omega^{P}=\left(\omega_{1}^{P}, \omega_{2}^{P}, \ldots \omega_{m}^{P}\right)^{\mathrm{T}}$, where $\omega_{i}^{P}(j=1,2, \ldots, n)$ is expressed as:

$$
\omega_{i}^{P}=\frac{1}{m(m-1)}\left(\sum_{j=1}^{m} p_{i j}+\frac{m}{2}-1\right) \quad(i \in M)
$$

(6) Reorder $r_{i}(i=1,2, \ldots, m)$ in descending order in accordance with $\omega_{i}^{P}(i \in M)$. Then we can rank all the alternatives $x_{i}$ and select the most desirable one in accordance with the value of $r_{i}$.

\section{Simulation}

Aircraft landing process is simulated for five times. The flight states of landing process are indicated in Figure 8-10, and final distributions of touchdown points are shown in Figure 11. Finally, the landing risk are evaluated.
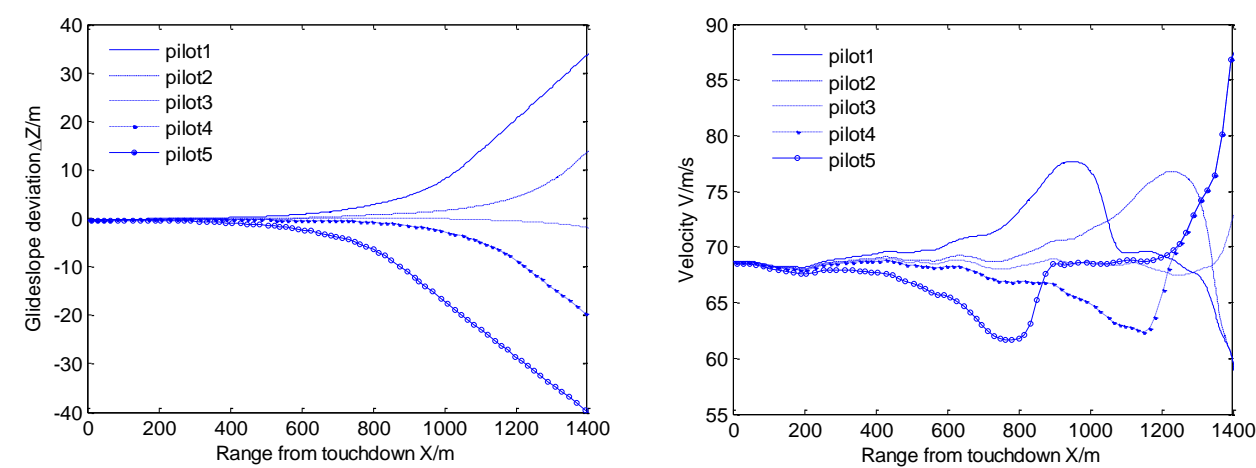

Figure 8. Glideslope Deviations Curves

Figure 9. Speed Curves

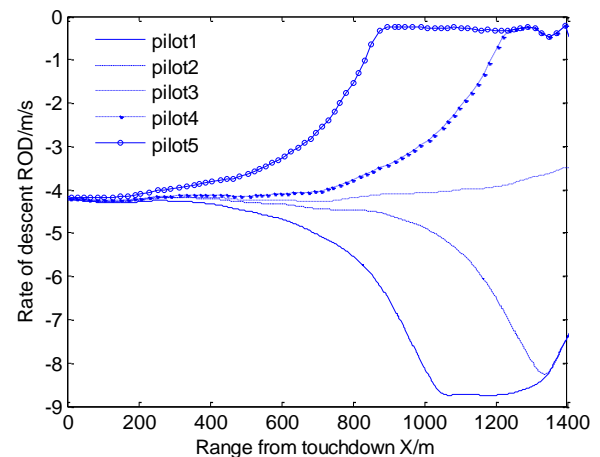

Figure 10. ROD Family of Curves

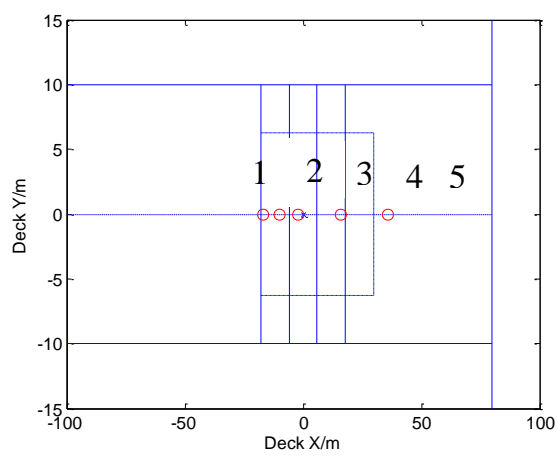

Figure 11. Distributions of Touchdown Points 
Landing signal officer (LSO) uses normal fuzzy linguistic variables to evaluate the performance of the voyages $x_{i}(i=1,2,3,4,5)$ at four reference points according to the attributes $u_{j}(\mathrm{j}=1,2,3)$, and constructs, respectively, the decision matrices $\boldsymbol{R}_{\boldsymbol{k}}$ $(k=1,2,3,4$, here as listed in Tables 4-7.

Table 4. Evaluation Matrix of Decision Maker d1 (X Point)

\begin{tabular}{cccc}
\hline Pilotlflight state & $u_{1}$ & $u_{2}$ & $u_{3}$ \\
\hline$x_{1}$ & {$[0.2,0.04]$} & {$[0.2,0.04]$} & {$[0.2,0.04]$} \\
$x_{2}$ & {$[0.5,0.05]$} & {$[0.3,0.04]$} & {$[0.3,0.04]$} \\
$x_{3}$ & {$[0.6,0.05]$} & {$[0.5,0.05]$} & {$[0.6,0.05]$} \\
$x_{4}$ & {$[0.4,0.05]$} & {$[0.1,0.04]$} & {$[0.3,0.04]$} \\
$x_{5}$ & {$[0.1,0.04]$} & {$[0.1,0.04]$} & {$[0.2,0.04]$} \\
\hline
\end{tabular}

Table 5. Evaluation Matrix of Decision Maker d2 (IM Point)

\begin{tabular}{cccc}
\hline Pilotlflight state & $u_{1}$ & $u_{2}$ & $u_{3}$ \\
\hline$x_{1}$ & {$[0.4,0.05]$} & {$[0.2,0.04]$} & {$[0.4,0.05]$} \\
$x_{2}$ & {$[0.6,0.05]$} & {$[0.5,0.05]$} & {$[0.6,0.05]$} \\
$x_{3}$ & {$[0.7,0.04]$} & {$[0.6,0.05]$} & {$[0.7,0.04]$} \\
$x_{4}$ & {$[0.5,0.05]$} & {$[0.3,0.04]$} & {$[0.3,0.04]$} \\
$x_{5}$ & {$[0.2,0.04]$} & {$[0.5,0.05]$} & {$[0.2,0.04]$} \\
\hline
\end{tabular}

Table 6. Evaluation Matrix of Decision Maker d3 (IC Point)

\begin{tabular}{cccc}
\hline Pilotlflight state & $u_{1}$ & $u_{2}$ & $u_{3}$ \\
\hline$x_{1}$ & {$[0.5,0.05]$} & {$[0.4,0.05]$} & {$[0.6,0.05]$} \\
$x_{2}$ & {$[0.7,0.05]$} & {$[0.6,0.05]$} & {$[0.7,0.04]$} \\
$x_{3}$ & {$[0.8,0.04]$} & {$[0.7,0.04]$} & {$[0.8,0.04]$} \\
$x_{4}$ & {$[0.6,0.05]$} & {$[0.5,0.05]$} & {$[0.5,0.05]$} \\
$x_{5}$ & {$[0.3,0.04]$} & {$[0.4,0.05]$} & {$[0.4,0.05]$} \\
\hline
\end{tabular}

Table 7. Evaluation Matrix of Decision Maker d4 (AR Point)

\begin{tabular}{cccc}
\hline Pilotlflight state & $u_{1}$ & $u_{2}$ & $u_{3}$ \\
\hline$x_{1}$ & {$[0.7,0.04]$} & {$[0.6,0.05]$} & {$[0.7,0.04]$} \\
$x_{2}$ & {$[0.8,0.04]$} & {$[0.7,0.04]$} & {$[0.8,0.04]$} \\
$x_{3}$ & {$[0.9,0.04]$} & {$[0.8,0.04]$} & {$[0.9,0.04]$} \\
$x_{4}$ & {$[0.7,0.04]$} & {$[0.7,0.04]$} & {$[0.6,0.05]$} \\
$x_{5}$ & {$[0.6,0.05]$} & {$[0.6,0.05]$} & {$[0.5,0.05]$} \\
\hline
\end{tabular}

(1) $d_{1}(\mathrm{X}): r_{1}^{(1)}=\operatorname{GFLWA}_{\omega}\left(r_{11}^{(1)}, r_{12}^{(1)}, r_{13}^{(1)}\right)=\sum_{j=1}^{3} \omega_{j} r_{1 j}^{(1)}=[0.2,0.04]$;

Similarly, $r_{2}^{(1)}=[0.38,0.044], r_{3}^{(1)}=[0.56,0.05], r_{4}^{(1)}=[0.26,0.044], r_{5}^{(1)}=[0.12,0.04]$. $d_{2}(\mathrm{IM}): r_{1}^{(2)}=[0.32,0.046], \quad r_{2}^{(2)}=[0.56,0.05], \quad r_{3}^{(2)}=[0.66,0.044], \quad r_{4}^{(2)}=[0.38,0.044], \quad r_{5}^{(2)}$ $=[0.32,0.044]$.

$d_{3}(\mathrm{IC}): r_{1}^{(3)}=[0.48,0.05], \quad r_{2}^{(3)}=[0.66,0.048], \quad r_{3}^{(3)}=[0.76,0.04], \quad r_{4}^{(3)}=[0.54,0.05], \quad r_{5}^{(3)}$ $=[0.36,0.046]$.

$d_{4}(\mathrm{AR}): r_{1}^{(4)}=[0.66,0.044], r_{2}^{(4)}=[0.76,0.04], r_{3}^{(4)}=[0.86,0.04], r_{4}^{(4)}=[0.68,0.042], r_{5}^{(4)}$ $=[0.58,0.05]$.

(2) Let $\omega^{D}=(0.0403,0.0638,0.1231,0.7728)^{\mathrm{T}}$ be the weight vectors of the attributes $u_{j}(\mathrm{j}=1,2,3)$ at all reference points. 
Use the NFLWA operator to aggregate the attribute value $r_{i}^{(k)}(i \in M, k=1,2,3,4)$ of the four standard positions into a overall attribute value of the alternative $x_{i}$ $(i=1,2, \ldots, m)$ :

$$
r_{1}=\operatorname{GFLWA}_{\omega^{D}}\left(r_{1}^{(1)}, r_{1}^{(2)}, r_{1}^{(3)}, r_{1}^{(4)}\right)=\sum_{j=1}^{4} \omega_{j}^{D} r_{1}^{(j)}=[0.5976,0.0447]
$$

Similar, $\quad r_{2}=[0.7196,0.0418], \quad r_{3}=[0.8228,0.0407], \quad r_{4}=[0.6267,0.0432], \quad r_{5}$ $=[0.5178,0.0487]$.

(3) Possibility-degree matrix:

(4) Ordering vector:

$$
\boldsymbol{P}=\left[\begin{array}{ccccc}
0.5 & 0.2267 & 0 & 0.4358 & 0.6656 \\
0.7733 & 0.5 & 0.2576 & 0.7118 & 0.9321 \\
1 & 0.7424 & 0.5 & 0.9530 & 1 \\
0.5642 & 0.2882 & 0.0470 & 0.5 & 0.7296 \\
0.3344 & 0.0679 & 0 & 0.2704 & 0.5
\end{array}\right]
$$

$$
\omega^{P}=(0.166405,0.23374,0.28477,0.18145,0.133635)^{\mathrm{T}}
$$

(5)Rank all the alternatives $r_{i}$ in accordance with the values of $\omega^{P}$. We can see that the ranking order is:

and the risk order is:

$$
r_{3}>r_{2}>r_{4}>r_{1}>r_{5}
$$

$$
\mathrm{Risk}_{3}<\mathrm{Risk}_{2}<\mathrm{Risk}_{4}<\mathrm{Risk}_{1}<\mathrm{R} \text { isk }_{5}
$$

The decision result shows that the landing risk of group 3 is the least. Comparing with Figure 5, correspondingly the touchdown point locates between the second cable and the third one, and it is closest to the desired touchdown, however, other voyages points distributions are far from the desired one, and the decision risk is increased. The decision result equates with the distributions of touchdown points, and it proves the practicality of this decision method.

\section{Conclusion}

This paper has presented possibility-degree algorithm of normal fuzzy variable, and introduced an improved multi-attribute group decision making approach. After establishing LSO-pilot-carrier-based aircraft model, it has built Safe Flight Area, and get relative attribute weighted vector. At last normal fuzzy multi-attribute group decision making has an application in landing risk evaluation of carrier-based aircraft. Simulation results show that the reasonable and application of the new algorithm.

\section{Acknowledgement}

The author would like to thank the anonymous referees for their valuable suggestions. This work was supported by the Natural Science Foundation of Heilongjiang Province of China (Grant Nos. F201349), Science and Technology Research Foundation of Heilongjiang Education Department (Grant Nos. 12531159), the Natural Science Foundation of Heilongjiang Province of China (Grant Nos. F201423) and the Natural Science Foundation of Heilongjiang Province of China (Grant Nos. F201210).

\section{References}

[1] T. Rudowsky, S. Cook and M. Hynes, "Review of the carrier approach criteria for carrier-based aircraft", Techinical report NAWCADPAX/TR-2002/71, (2002). 
[2] Z. S. Xu and Q. L. Da, "Multi-attribute decision making based on fuzzy linguistic assessments", Journal of Southeast University (Natural Science Edition), vol. 32, no. 4, (2002), pp. 1-3.

[3] Z. S. Han and P. D. Liu, "Multiple attribute decision making method based on trapezoid fuzzy linguistic variables", Fuzzy Systems and Mathematics, vol. 25, no. 3, (2011), pp. 119-126.

[4] F. Herrera and L. Martinez, "An approach for combing numerical and linguistic information based on the 2-tuple fuzzy linguistic representation model in decision making”, International Journal of Uncertainty, Fuzziness and Knowledge-Based Systems, vol. 8, (2000), pp. 539-562.

[5] D. F. Li and J. B. Yang, "Fuzzy liner programming technique for multi-attribute group decision making in fuzzy environments", Information Sciences, vol. 158, (2004), pp. 263-275.

[6] Z. Xu, "Group decision making with triangular fuzzy linguistic variables", LNCS, vol. 4881, (2007), pp. $17-26$.

[7] X. C. Liang and S. F. Chen, "Multiple attribute decision making method based on trapezoid fuzzy linguistic variables", Journal of Southeast University, vol. 24, no. 4, (2008), pp. 478-481.

[8] P. Liu and S. Yu, "The extended TOPSIS based on trapezoid fuzzy linguistic variables", Journal of Convergence Information Technology, vol. 5, no. 4, (2010), pp. 38-53.

[9] R. K. Heffley, "Outer-loop control factor for carrier aircraft", (1990); USA.

[10] R. A. Hess, "Simplified Approach for modeling pilot pursuit control behaviour in multi-loop flight control taks", Institution of mechanical engineer, vol. 220, no. 2, (2006), pp. 85-102.

[11] NAVAIR 00-80T-104, NATOPS Landing signal officer manual, (2001).

[12] X. J. Qu and H. L. Cui, "Variable strategy pilot model of carrier landing approach", Journal of Beijing University of Aeronautics and Astronautics, vol. 29, no. 11, (2003), pp. 993-997.

[13] Z. S. Xu, "Study on methods for multiple attribute decision making under some situations", School of Economics \& Management, Southeast University, (2002).

[14] L. Liu, Y. X. Chen and Z. H. Ge, "Approach to the multi-attribute linguistic decision making and its' application", System Engineering and Electronics, vol. 31, no. 1, (2009), pp. 113-115, 207.

[15] Y.X. Zhang, "Analysis on mine coal dust explosion dangree base on normal fuzzy function”, Coal Engineering, vol. 7, (2009), pp. 72-74.

[16] Z. H. Lv, C. B. Chen and P. Y. Qin, "Normal distribution fuzzy sets-A new extension of fuzzy sets", Computer Science, vol. 33, no. 11, (2006), pp. 1-14, 173.
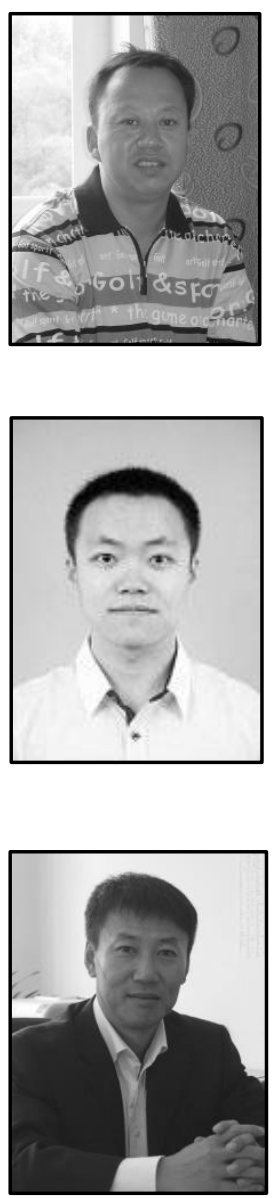

Xiao-dong Su is an professor of Harbin University of Commerce and he is the member of council of the China Software Industry Association, vice president of Electronics Experiment Teaching Research Council of Universities in Heilongiiang, member of Heilongjiang Computer Society Education and Training Professional Committee. His recent research interests are in information detection and estimation, management information systems. 